\title{
BRACHIAL ARTERY RUPTURE DUE TO AN EXOSTOSIS: BRIEF REPORT
}

\author{
A. NEVELSTEEN, P. PYPE, P. BROOS, R. SUY
}

Exostoses are mostly asymptomatic, but they may irritate surrounding structures. Vascular complications have occasionally been reported around the knee (Paul 1953; Hasselgren et al. 1983). We report a case of brachial artery rupture due to an exostosis of the humerus.

Case report. A 36-year-old man was admitted with acute swelling of the left shoulder. There was no history of trauma or undue exertion. Examination revealed a diffuse and tender tumour of the left upper arm. The vascularity of the limb looked normal, but radial pulsations were felt only with the arm in abduction. Radiographs showed a mass in the left axilla and a large irregular sessile exostosis of the upper humerus. CT scanning confirmed a mass of relatively high density into which the exostosis protuded (Fig. 1). Angiography showed medial deviation of the brachial artery with a localised irregularity of the arterial wall just below the circumflex arteries (Fig. 2). There was no extravasation of contrast medium.

The presumptive diagnosis of arterial trauma due to the exostosis was confirmed at operation, at which a large organised haematoma was removed. An irregular perforation was found in the brachial artery. This was repaired by local resection and end-to-end anastomosis and the exostosis was excised completely. Microscopic examination revealed normal bone tissue with an overlying bursa; there were no cartilaginous remnants.

Postoperatively radial pulsations were present even with the arm in adduction. A paresis of the radial nerve recovered completely. The patient was discharged after eight days and has had no further trouble.

Discussion. The first reported case of arterial trauma by an exostosis was by Paul (1953). Since then, others have been reported and in 1983 Hasselgren et al. collected 22 cases. All these, however, were femoral or tibial exostoses. As far as we know, only one case similar to ours has previously been reported. This was a brachial artery aneurysm caused by a humeral exostosis in a 15year-old girl (Cachera, Letournel and Kieffer 1970).

About $50 \%$ of patients with vascular complications due to exostoses give a history of trauma, and in less than half the cases are there multiple exostoses. Diagnosis is based on the angiographic findings and treatment depends on the nature of the lesion. Local resection and

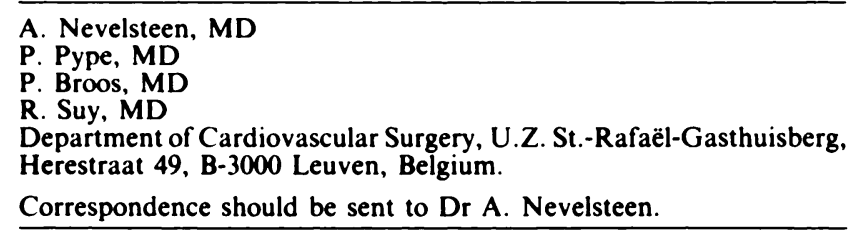

(C) 1988 British Editorial Society of Bone and Joint Surgery 0301-620X/88/4R66 \$2.00

J Bone Joint Surg [Br] 1988;70-B:672.

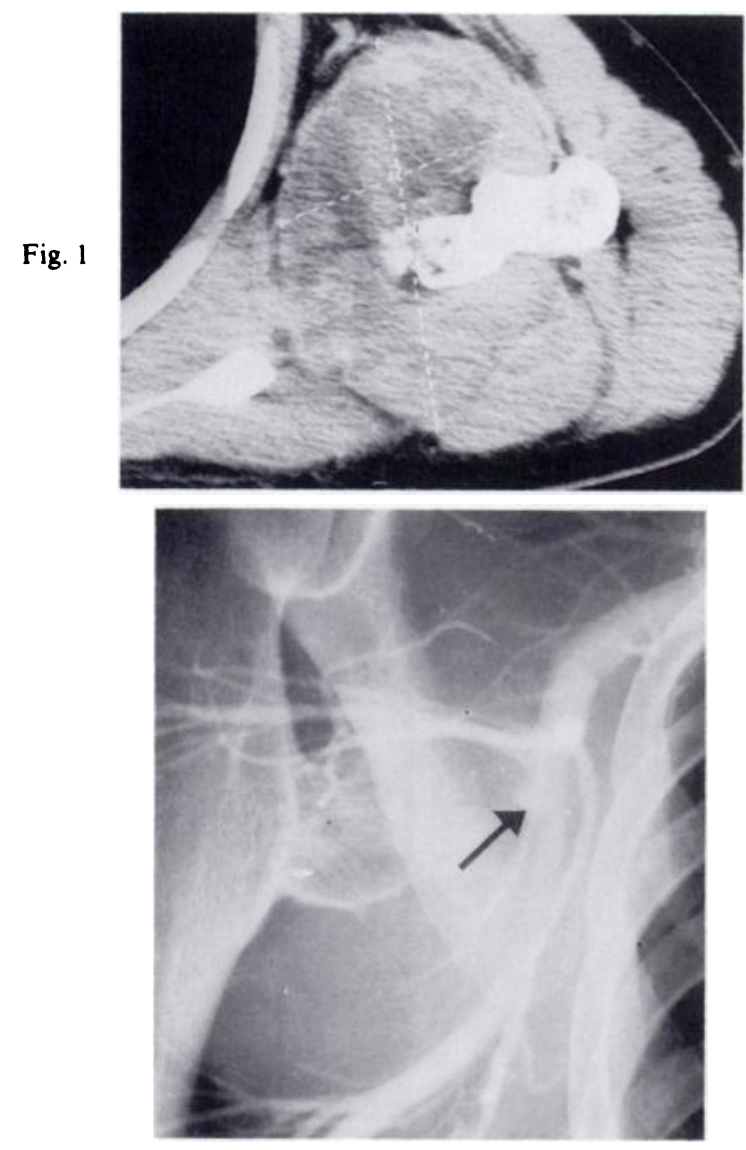

Fig. 2

end-to-end anastomosis will suffice for pseudo-aneurysms (Hershey and Lansden 1972), but with thrombosis or a true aneurysm, segmental interposition, preferably with the use of an autologous vein, is mandatory (Boscher et al. 1984). The exostosis, of course, should be removed completely. Whether an exostosis in the vicinity of an artery should be removed prophylactically remains uncertain, but as all the reported vascular complications have been repaired successfully, in our opinion a "wait and see" policy is justified.

\section{REFERENCES}

Boscher Y, Lescalie F, Moreau P, Enon B, Chevalier JM, Pillet J. Thrombose Artérielle poplitée sur ostéochondrome de l'extrémité supérieure du tibia: propos d'un cas. J Chir (Paris) 1984;121:327-30.(Eng. abstr.)

Cachera JP, Letournel E, Kieffer E. Un cas d'anéurysme artériel compliquant une exostose ostéogénique de l'extrémité supérieure de l'humérus. J Chir (Paris) 1970;99:39-44.

Hasselgren P-O, Eriksson B, Lukes P, Seeman T. False popliteal aneurysm caused by exostosis of the femur. $J$ Cardiovasc Surg $1983 ; 24: 540-2$.

Hershey SL, Lansden FT. Osteochondromas as a cause of false popliteal aneurysms: review of the literature and report of two cases. J Bone Joint Surg [Am] 1972;54-A:1765-8.

Paul M. Aneurysm of the popliteal artery from perforation by a cancellous exostosis of the femur: report of a case. $J$ Bone Joint Surg [Br] 1953;35-B:270-1. 